\title{
Mutual Fund Investment Style Consistency and Risk-Adjusted Performance
}

\author{
Justus Loick ${ }^{1}$
}

\begin{abstract}
While it is commonly agreed on that a mutual fund's investment style influences its returns to investors, academia has not fully explored the relationship between a mutual fund's consistency with its stated investment style and risk-adjusted performance. The study at hand employs a novel consistency ratio by means of the return-based style analysis for U.S. equity mutual funds to investigate that relationship. Based on their consistency scores, mutual funds are subsequently divided into quintiles and compared for their riskadjusted performance. Evidence is found that investment style consistency does influence risk-adjusted returns and that the financial crisis had a major impact on that relation. While a convex curve describes the relationship between style consistency and fund performance before the financial crisis, it reversed into a concave curve afterwards. This study contributes to current research by going beyond a linear relationship between mutual fund investment style consistency and risk-adjusted performance, commonly assumed in prior studies.
\end{abstract}

\section{Introduction}

In today's financial markets, professional asset managers face myriad investment opportunities to invest their client's money in. Investment vehicles can be divided into four broad asset classes, namely stocks, real estate, bonds, and commodities. The heterogeneity of these asset classes points to the diversity of investment opportunities. Yet, even within each asset class, investors face considerable variety to diversify their portfolio. In the overall equity asset class, investment vehicles, such as equity mutual funds, have the possibility to invest in distinct types of stocks with very different risk profiles and expected returns. Different investment vehicles produce distinct return distributions and hence attract divergent subgroups of the overall investment community. To put it in Brown's (2015) words: "Investment style matters, and it matters a lot".

Mutual funds are a collection of stocks, bonds, and similar assets and represent one of the most popular investment security types. They allow investors to diversify their assets and get exposure to a certain investment style with only small initial investments. People entrust their money to mutual funds for multiple reasons, but mainly because they believe asset managers can achieve better investment returns than they could do with their own resources (Brown, Van Harlow, \& Zhang, 2009). The decision process for a specific investment trust is complex and crucially depends on expectations of the future performance of the respective fund. Expectations, in turn, are driven by the offering memorandum, which presents the targeted investment style of the trustee. Not surprisingly, asset managers' consistency in their stated investment style is of utmost interest for the investment community. A trustee's ability to maintain a coherent investment style enables individual investors to manage the risk and return profile of their aggregate portfolio and is a key decision criterion for the selection of mutual funds. If the investment style experiences any deviations, there must be a good reason for the fund manager to do so.

\footnotetext{
1 Justus Loick received a bachelor degree in International Business at Maastricht University in 2016. At the moment he undertakes a gap year with various internships before pursuing a Master in Financial Economics at Oxford University. Contact: j.loick@gmx.de
} 
A topic, which has not been very popular in academia until now but is on the way to become a "hot" research topic due to its essentiality for both research and practitioners, is the relationship between a mutual fund's investment style consistency and its risk-adjusted performance. In other words, do mutual funds which are consistent with their stated investment style outperform their peers that let their investment style drift over time?

Current research on the impact of investment style consistency both lacks a strong theoretical model and embeds largely controversial empirical evidence. Proponents of the positive relationship between style consistency and future performance point to the lower portfolio turnover and lower associated transaction costs of funds with a more style-consistent investment approach. Furthermore, studies suggest a certain amount of "economies-of-style-specialization" due to expertise building, and a lower risk of asset misallocations for mutual funds without style shifts. On the contrary, the opponents of the positive effect of style consistency promote the view of skillful fund managers as generalists who can apply valuation skills over different style categories to engage in profitable stock picking. They argue that style-consistent portfolios are unlikely to have the same upside potential than mutual funds with successful style-rotation in the market. To complicate issues, both strands of research find empirical evidence for their theories.

The research aims to contribute to the research field by analyzing the existing gap on the relationship of mutual funds' investment style consistency and future risk-adjusted performance. Although extensive research has been directed to the type of investment style that provides superior performance, academia and practitioners have not fully discovered the effect of investment style consistency of mutual funds yet. Instead of solely analyzing the mechanics of the abovementioned relationship over a certain period, this study goes one step beyond. It further filters out the impact of the financial crisis on the direction and strength of that relationship. In the process of finding an answer to that issue, individual funds with investment style inconsistencies are examined with respect to the extent and direction of their deviation.

The paper is structured as follows: Firstly, a literature review is conducted in order to construct a solid theoretical framework. As a next step, the concrete research hypothesis is presented. Thirdly, both the returnbased style consistency method as employed in this research to measure style consistency and the overall research methodology are discussed. Finally, after a presentation of the results, the paper concludes with a discussion and the limitations of the study at hand.

\section{Theoretical Framework}

The theoretical framework aims to firstly introduce the reader into the essential literature on equity investments and the dimensions by which equity funds are classified. The second part provides an overview on current research on investment style consistency and risk-adjusted performance of funds.

\subsection{Equity Investment Styles}

The investment performance of professional asset managers has been a matter of concern for years, especially since the 1980s and 1990s when financial securities, such as mutual funds, hit record highs and provided investors with overwhelming returns. Mutual funds are investment vehicles made up of a pool of funds collected from many investors for the purpose of investing in different classes of securities. They are typically grouped according to the type of securities they invest in and hence attract different groups of investors based on their stated investment style. As common in most other research on that field, the study at hand defines a styleinconsistent mutual fund as a fund which stated to invest into a specific investment style, but whose actual returns resemble another investment style more than the stated one (Brown, Van Harlow, \& Zhang, 2009; Dor \&
Marble
2 Research
Papers 
Jagannathan, 2002). At this point, it is important to resume the different investment styles fund managers can invest in.

For equity investments, the work of Fama and French $(1992,1993)$ with their multi-factor asset-pricing model has greatly contributed to the classification of stocks based on certain firm-related attributes. Nowadays, investment portfolios are generally classified along two dimensions: 1) firm size and 2) price-earnings ratio.

The former dimension is approximated by a firm's total market capitalization and is divided into small-, mid-, and large-cap. Small-cap firms empirically provide investors with higher returns compared to large-cap firms since they entail additional risks factors not captured by the CAPM model. Several studies attribute the equity premium for small cap firms to a lack of information concerning the true parameters for future return distributions as compared to large-cap firms (Banz, 1981; Barry \& Brown, 1984). Reinganum \& Smith (1983) further explain the premium with "higher transaction costs associated with maintenance of a well-diversified small firm portfolio [compared to] a large firm portfolio" (p.225) as many small-cap firms are illiquid or delisted. The latter dimension of Fama and French's classification refers to the ratio of the market price to a firm's current earnings and book value, and functions as an indication of growth expectations. Equity investments are segmented into value (low price-to-earnings and price-to-book ratio), blend (medium price-to-earnings and price-to-book ratio), and growth (high price-to-earnings and price-to-book ratio) stocks. Fama and French argue that value stocks offer greater expected returns as a compensation for a higher variable risk of financial distress costs and persistently lower earnings empirically associated with value stocks (French \& Fama, 1993; French \& Fama, 1995).

Although academia partly disagrees on the specific reason for the occurrence of the small-cap and value premium, empirical evidence can be found for the existence of those premiums in financial markets (Brown, Van Harlow, \& Zhang, 2009). Therefore, returns differ between equity investment styles and they cannot be easily compared for performance appraisal.

Combining the two dimensions into $3 \times 3$ grids defines investment portfolios based on firm size and relative valuation in order to distinguish different types of equity-focused funds. This classification is not only employed by major investment research platforms (Morningstar and CRISP) to classify stocks, but also major market indices are established to mirror the nine distinct investment styles, such as certain Russell indices.

A heat map of style-specific equity Russell indices from 2003 to 2015 provides a first glance on the performance differences and return volatility among investment styles over time.

As an illustration in reference to figure 1, we take the example of a mutual fund manager without a consistent investment style, neglecting his offering memorandum and stated investment style. After incredible results of small-cap value stocks in 2006, he is likely to invest in these stocks in 2007 to benefit from the outstanding returns. In the end of 2007, after small-cap value stocks turn out to be the worst performing group, he liquidates his stakes only to find out that small-cap value stocks in 2008 once more have the best performance. Jumping on the train again in 2009 , he is left with the second-worst performing stocks again. 


\begin{tabular}{|c|c|c|c|c|c|c|c|c|c|c|c|c|}
\hline 2008 & 2004 & 2005 & 2006 & 2007 & 2008 & 2009 & 2010 & 2011 & 2012 & 2013 & 2014 & 2015 \\
\hline SG & MN & $\mathrm{MB}$ & SV & LG & SV & MG & SG & LG & MN & SG & MN & LG \\
\hline 48.54 & 23.71 & 12.65 & 23.48 & 11.81 & -28.92 & 46.29 & 29.09 & 2.64 & 18.51 & 43.30 & 14.75 & 5.67 \\
\hline SB & SV & $\mathrm{MN}$ & LV & MG & SB & $\mathrm{MB}$ & SB & LB & SV & SB & LV & LB \\
\hline 47.25 & 22.25 & 12.65 & 22.25 & 11.43 & -33.79 & 40.48 & 26.85 & 1.50 & 18.05 & 38.82 & 13.45 & 0.92 \\
\hline SV & $\mathrm{MB}$ & MG & MN & $S G$ & LV & LG & MG & LV & LV & MG & LB & MG \\
\hline 46.03 & 20.22 & 12.10 & 20.22 & 7.05 & -36.85 & 37.21 & 26.38 & 0.39 & 17.51 & 35.74 & 13.24 & -0.20 \\
\hline MG & SB & LV & SB & LB & LB & SG & $\mathrm{MB}$ & $\mathrm{MN}$ & $\mathrm{MB}$ & $\mathrm{MB}$ & MB & SG \\
\hline 42.71 & 18.33 & 7.05 & 18.37 & 5.77 & -37.60 & 34.47 & 25.48 & -1.38 & 17.28 & 34.76 & 13.22 & -1.38 \\
\hline MB & LV & LB & LB & MB & LG & MN & MN & MB & LB & SV & LG & MB \\
\hline 40.06 & 16.49 & 6.27 & 15.46 & 5.60 & -38.44 & 34.21 & 24.75 & -1.55 & 16.42 & 34.52 & 13.05 & -2.44 \\
\hline MN & MG & LG & $\mathrm{MB}$ & LV & MN & LB & SV & MG & SB & LG & MG & LV \\
\hline 38.07 & 15.48 & 5.26 & 15.26 & -0.17 & -38.44 & 28.43 & 24.5 & -1.65 & 16.35 & 33.48 & 11.90 & -3.83 \\
\hline LV & SG & SV & SG & MN & SG & SB & LG & SG & MG & $\mathrm{MN}$ & SG & SB \\
\hline 30.03 & 14.31 & 4.71 & 13.35 & -142 & -38.54 & 27.17 & 16.71 & -2.91 & 15.81 & 33.46 & 5.60 & -4.41 \\
\hline LB & LB & SB & MG & SB & $\mathrm{MB}$ & SV & LB & SB & LG & LB & SB & $\mathrm{MN}$ \\
\hline 29.89 & 11.40 & 4.55 & 10.66 & -157 & -41.46 & 20.58 & 16.10 & -4.18 & 15.26 & 33.11 & $\begin{array}{r}4.89 \\
.\end{array}$ & -4.78 \\
\hline LG & LG & $S G$ & LG & SV & MG & LV & LV & SV & SG & LV & sv & SV \\
\hline 29.75 & 6.30 & 4.15 & 9.07 & -9.78 & -44.32 & 19.69 & 15.51 & -5.50 & 14.59 & 32.53 & 4.22 & -7.47 \\
\hline
\end{tabular}

- $\quad$ LV =Russell $1000 @$ Value Index (Large-cap Value)

MG = Russell Midcap $($ Growth Index (Mid-cap Growth)

- $\quad$ LB =Russell 1000ß) Index (Large-cap Blend

- $\quad S V=$ Russell $2000 @$ Value Index (Small-cap Value)

- $\quad L G=R u s s e l l 1000 @$ Growth Index (Large-cap Growth) - $\quad$ SB = Russell 2000@ Index (Small-cap Blend)

- $\quad M V=$ Russell Midcap $B$ Value Index (Mid-cap Value) SG = Russell 2000ß Growth Index (Small-cap Growth)

- $\quad \mathrm{MB}=$ Russell Midcap $B$ Index (Mid-cap Blend)

Figure 1. Style-specific Russell indices

The above-mentioned example is anything but far-fetched. Froot \& Theo (2008) find evidence for institutional investors having stronger preferences for large-cap stocks when they recently delivered high returns relative to small-cap stocks. In more general terms, Barberis, \& Shleifer (2003) find that "if an asset performed well last period, [...] the style is likely to keep attracting inflows from switches next period" (pp. 183-184) as investors consider it as a "hot" style.

This example is meant to illustrate a crucial point, namely that returns of equity investment classes differ and relative performances change over time. While it is recognized that specific styles deliver higher returns in the long-term, it is far from certain how they perform in upcoming financial periods due to their higher levels of volatility in the underlying return distribution. With superior information, mutual fund managers would be able to pick stocks from the best performing investment style every year. According to that assumption, fund managers with excellent stock picking skills and an overarching idea of market developments are deemed to outperform their peers. Yet, this superior knowledge contradicts the efficiency principle of financial capital markets, which assumes market prices to "fully reflect available information so that there exists no strategy from which traders can profit consistently" (Lai \& Lai, 1991, p. 567).

Therefore, it remains ambiguous up to that point whether fund managers who let their investment style drift over time for style-rotation deliver better risk-adjusted results than their style-consistent peers do. In line with Brown et. al. (2009), the underlying axiom is that the decision to consistently invest in a portfolio with a high correlation to the designated style benchmark, i.e. a style-consistent portfolio, does have an impact on returns, but the probable direction of that relationship needs to be examined.

\footnotetext{
$4 \mid$\begin{tabular}{l|l} 
Marble \\
Research
\end{tabular} Papers
} 


\subsection{Investment Style Consistency and Fund Performance}

Current research on the impact of investment style consistency lacks a strong theoretical model and two strands of studies find evidence for both a positive and negative impact of investment style-consistency.

Barberis \& Schleifer (2003) in their famous work on style investing investigate the co-movement of assets within the same investment style and between different styles. While the authors do not deny the possibility for profits made from well-timed style rotations, they assert that "patterns in security prices are complex [so that] arbitrage is risky and consistent profits hard to come by" (p. 190). According to the authors, fund managers who closely follow a specific investment style are less likely to make asset misallocation as illustrated in the example above.

Brown, Harlow \& Zhang (2009) point to the fact that "more style-consistent funds exhibit less portfolio turnover and $[\ldots]$ lower transaction costs than funds that allow their style to drift" (p. 3). The authors find evidence for a positive influence of style consistency on both absolute and risk-adjusted future returns from for a sample of mutual funds between 1980 and 2006, which included all funds listed in the CRSP Mutual Fund database.

In a similar fashion, it is possible that style shifting stems from "ill-motivated trades of unskilled or agency-prone fund managers who trade to increase their personal compensation" according to Huang, Sialm \& Zhang (2011, p. 1). Fund managers' behavior can be explained by a certain convex flow performance relation in whom investors are inclined to invest in funds with outstanding returns and do not withdraw their money to the same extent when performance worsens. This incentivizes fund managers to outperform their peers in some periods by investing in "hot" investment styles despite their poor trading skills. On top, the paper argues that frequently reshuffling the portfolio for equity investment styles with a certain momentum might distract fund managers from investing in the most promising, long-term securities.

In his paper, Wermers (2012) contrasts two opposing views on the relationship of crise and risk-adjusted performance: The former emphasizes the gathering of expertise and potential connections with corporate executives for institutional investors that help in creating "economies-of-style specialization" (p. 1). The latter view points to the fact that talented managers are generalists who can apply valuation skills across different style categories of stocks to identify underpriced securities. Werner finds empirical evidence for the second view such that fund managers with style drifts deliver better future portfolio performance, even after accounting for transaction costs. The research investigates a sample of U.S. equity mutual funds from 1975 to 1994.

Assness, Friedman, Krail \& Liew (2000) assert that although more style-consistent portfolios might help funds in avoiding underperformance relative to peers, it is unlikely to have the same upside potential that accrues to managers who manage to precisely time style-rotations in the market. While some argue that style and market timing of mutual funds is largely hampered by institutional constraints for mutual funds, such as an inability to short-sale, the same effect can be achieved by reshuffling portfolio weights and the cash components in the absence of any short-selling activities (Jiang, Yao, \& Yu, 2007).

In an empirical study, Bollen \& Busse (2001) find evidence for positive market timing results for mutual funds drifting between value and growth stocks when measuring daily returns as compared to monthly and annual ones. Similar studies assert that while style consistency is reasonable for long-term investors with strong opinions on the returns of specific styles, carefully considered style rotations can indeed be value-enhancing (Levis \& Liodakis, 1999; Zhao, 2009).

Based on existing literature and empirical findings, a visualized conceptual framework of the relationship between mutual funds' investment style consistency and risk-adjusted performance can be depicted as below. Illustrated variables aim to give a basic intuition and are far from being exhaustive. While mediator variables speak to how or why a specific effect occurs, the moderator variable influences the strength of that relationship (Baron \& Kenny, 1986). For instance, while style inconsistency generally leads to lower net returns due to 
transactions costs caused by portfolio reshuffling, these costs can be equalized by the timing ability of an asset manager with superior stock picking abilities across investment styles.

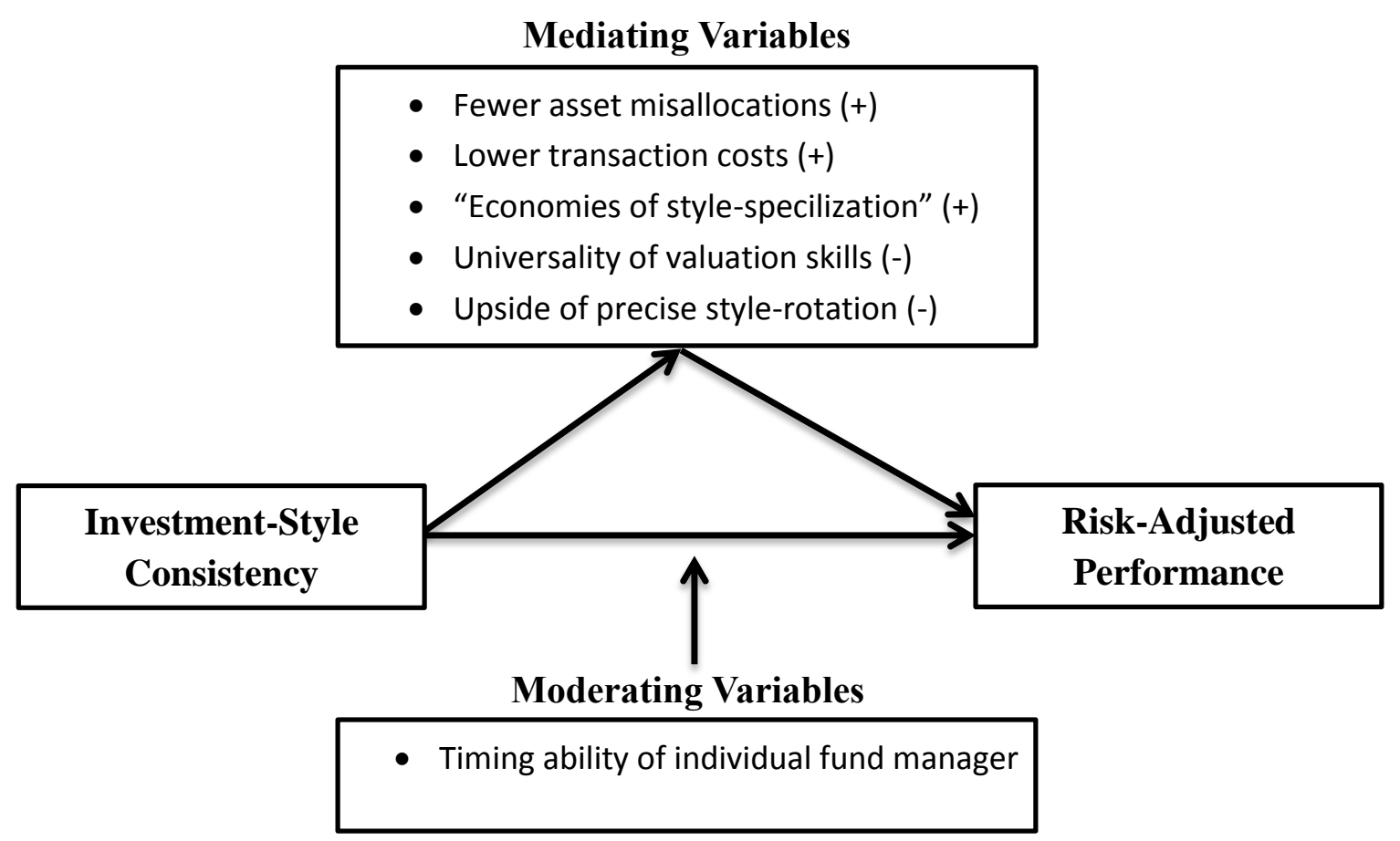

Figure 2. Theoretical framework

To sum up, it is not only a relatively young research field, but it further embeds controversial arguments for the direction of the relationship. There is plausible argumentation for both strands of research and the ongoing debate on investment style consistency and fund returns, therefore, needs to be backed by strong empirical studies. Only empirical results can reveal which of the mediating and moderating variables eventually prevail. Figure 2 presents an illustrative overview of the theoretical framework

\section{Research Hypothesis}

The research aims to contribute to the existing gap in current research by analyzing the investment consistency of U.S.-based equity mutual funds with their stated investment style and its relationship to one-year-ahead fund performance.

The research aims to answer the main question: "What is the relationship between mutual funds' investment style consistency and future risk-adjusted performance?" In order to thoroughly answer this research questions, the study at hand filters out the impact of the financial crisis on the investigated relationship since the crisis likely had an influence on the behavior of asset managers. This process enables to detect changes, if any, in the relationship between style consistency and fund performance. Hence, the research is constituted of two main questions. "What is the relationship between mutual funds' investment style consistency and the future riskadjusted performance before the financial crisis?" and "What is the relationship between mutual funds' investment style consistency and the future risk-adjusted performance after the financial crisis?"

\footnotetext{
6 \begin{tabular}{l|l} 
Marble \\
Research \\
Papers
\end{tabular}
} 
In the process of finding an answer to this issue, individual funds with investment style inconsistencies are examined with respect to the direction and extent of their deviation. More specifically, the research both provides a glance on the investment styles that most often embed style-inconsistent funds and shows to which benchmarks they deviate. Overall, the research enables a comprehensive understanding for both researcher and practitioners to examine the probability of dealing with style-inconsistent mutual funds for all nine investment styles and how style inconsistency affects future fund performance in the respective category.

While the upside potential for in-time style rotations should not be neglected, above-mentioned arguments for a positive relationship, including transaction costs for portfolio turnover and the potential for asset misallocations are likely to have a strong impact. These facts promote a decent probability for a positive sign of the relationship between style consistency and future fund performance. However, due to the lack of consistent empirical results and a strong theoretical model, the research does not establish a hypothesis with a fixed sign of the relationship at this point.

\section{Methodology}

The following section in detail explains the return-based style analysis as employed in the study at hand, specifics of the database and the data analysis part.

\subsection{Return-Based Style Analysis}

In investment research, two popular methods to measure investment style consistency of investment vehicles are prevalent. Under the holding-based approach, individual securities held in a portfolio are examined for their characteristics, which determine whether a mutual fund follows the investment style stated in its offering memorandum (Brown, Van Harlow, \& Zhang, 2009). Although this approach is very intuitive and the most natural way to assess style consistency, it is accompanied with several difficulties. It partly suffers from inaccuracy since holding data for funds are usually only captured at the end of each quarter and therefore represent infrequent and lagged observations. Furthermore, investors are not able to track whether a mutual fund changes its holdings between quarterly reporting. Hence, reported holdings could be subject to "window dressing effects" (Brown, Van Harlow, \& Zhang, 2009, p. 9).

In contrast, fund return data can be measured over much shorter time intervals, up to daily figures, which allow delineating the difference between actual and self-reported investment behavior. In fact, style consistency can be estimated by comparing a mutual fund's earned returns with the returns of a style-specific index, which represents the aggregate performance of other funds in the stated objective group (Shukla, Kim, \& Tomas, 2000). This process involves regressing a fund's past returns against all respective returns style indices, representing the entire investment universe available for equity-focused fund managers. These include all nine style-specific equity Russell indices, the four-weeks Treasury bill rate and the 20-years Government bond rate. The objective group indices are weighted-average returns of all stocks in that investment style. The regression can be formally expressed by a multi-factor model as shown below.

$$
R_{j t}=\sum_{k=1}^{11} b_{j k} \cdot R_{k t}
$$

where $R_{j t}=$ Return of mutual funds $j$ at time $t ; b_{j k}=$ Regression parameter (called beta) of one of the eleven objective indices; $R_{k t}=$ Return of index $k$ at time $t$. 
In general terms, the higher the correlation between two return distributions, the higher the regression parameter (i.e. beta) for the respective index and the more weight within the portfolio is allotted to that specific style. Since a Russell index represents the investment universe for a distinct investment style, the respective beta value provides a measure of the extent to which a mutual fund has followed that specific style. If the beta scores for either the Treasury bill rate or Government bond rate are high, there is evidence that mutual fund managers did not invest in the stated equity investment style, but invested the trusted money in current or saving accounts. This clearly represents a deviation from its initial investment objective. In general terms, if at least one of the ten other betas is higher than the beta for the style-specific index, a mutual fund is classified as being inconsistent in its investment style.

To calculate consistency scores with the return-based style analysis, all relevant mutual funds with an unchanging stated investment style over the time period are considered. Funds that have explicitly changed its investment style cannot not be compared to a single objective index any longer and do not provide meaningful regression results. Even if a mutual fund has followed the declared styles and therefore can be classified as being perfectly consistent, the analysis aggregates regression parameters over the total period and may show multiple significant positive beta scores. Without further analysis, these mutual funds would have been classified as an inconsistent and misclassified fund. To avoid such a misinterpretation and get reliable values for the consistency scores, only funds with a single Lipper Classification Code, i.e. a consistent stated investment style, are included in the analysis.

\subsection{Data Sample}

The sample was taken from the U.S. equity mutual funds database from 2003 to 2015 provided by Center of Research and Security Prices (CRSP) hosted from Wharton Research Data Services (WRDS) from the University of Pennsylvania. CRSP is in the possession of some of the largest and most comprehensive historical databases in mutual fund and stock market data. Mutual funds have been divided into the following nine investment style categories according to the Lipper Classification Code: Large-cap Value, Large-cap Blend, Large-cap Growth, Mid-cap Value, Mid-cap Blend, Mid-cap Growth, Small-cap Value, Small-cap Blend, and Small-cap Growth. Lipper Classification Codes are assigned according to the wording a mutual fund uses in its offering memorandum to explain how it intends to invest (CRSP, 2016). Hence, it is a good measure of the fund's stated investment style, which functions as the base line to compare whether a mutual fund invested inconsistently to its declared benchmark.

As explained under section 4.1., the sample only includes mutual funds with a consistent Lipper Classification Code throughout the time to get reliable values for the consistency scores. The research is solely focused on U.S. equity mutual funds due to the American market's outstanding transparency and availability of information on security prices. Furthermore, only mutual funds with at least three years of observations are being considered, since at least two years are required for an accurate consistency score and one further year of return data is necessary to measure subsequent one-year-ahead risk-adjusted performance. Overall, the paper restricts itself to working with existing, i.e. secondary, databases and there is no sampling method as the entire database of eligible U.S. equity mutual funds is used. After all, the data sample is comprised of 2867 U.S. equity mutual funds of which 1191 are investigated before and 1676 are investigated after the financial crisis. The research methodology thus avoids any data snooping biases in which a small data set is used more than once for inferences or model selection and there is no possibility that "any satisfactory results obtained may simply be due to chance rather than to any merit inherent in the method yielding the results" (White, 2000, p. 1115).

Since the financial crisis had a major impact on the work and the behavior of professional asset managers, the dataset will be split into a pre- and post- financial crisis period. The first one ranges from January 2003 until July

\footnotetext{
8 Marble

8 Research Papers
} 
2008 and the second one ranges from August 2008 until December 2015. Splitting the dataset enables to explore the effect the financial crisis had on the relationship between investment style consistency and fund performance.

\subsection{Data Analysis}

The data analysis consists of two parts: The former is to establish a measure for investment style consistency and latter is to establish the link between the consistency score and one-year-ahead risk-adjusted performance of mutual funds. The two parts are described in the subsequent section.

By means of return-based style analysis as explained under section 4.1., eleven beta scores are calculated for each mutual fund. Mutual funds are declared as misclassified, inconsistent funds once the benchmark index's beta of its stated investment style is smaller than at least one of the remaining ten beta scores. Once that benchmark index's beta has the highest coefficient in the regression, the mutual fund is classified as a wellclassified, consistent fund.

For a well-classified mutual fund $j$, the consistency score $C_{j}$ can be calculated as follows:

$$
C_{j}=\left(10 \beta_{j i}-\sum_{k=1}^{10} \beta_{j k}\right) / 10 ;
$$

where $\beta_{j i}=$ Beta of the benchmark index $i ; b_{j k}=$ Beta of the other objective indices.

For a mutual fund $j$ that is declared as a misclassified fund, the consistency score is given by the following equation:

$$
C_{j}=\sum_{k=1}^{10}\left(\beta_{j i}-b_{j k}\right) \text { for all } \beta_{j k} \text { such that } \beta_{j i}<\beta_{j k}
$$

where $\beta_{j i}=$ Beta of the benchmark index $i ; b_{j k}=$ Beta of the other objective indices

The equations as given above return consistency scores from 1 for totally well-classified funds (where $\beta_{j i}=1$ and $\sum_{k=1}^{10} b_{j k}=0$ ) to -1 for totally misclassified funds (where $\beta_{j i}=0$ and $\sum_{k=1}^{10} b_{j k}=1$ ). The distribution of consistency scores for well-classified funds ranges from 1 to 0 and the distribution of consistency scores for misclassified funds ranges from approximately 0 to -1 . The model is robust as consistency scores for well-classified funds are always higher than scores for misclassified funds and more consistent funds always receive a higher consistency score. Eventually mutual funds are to be divided into quintiles based on the value of their consistency scores in an overall list of all funds and within each of the nine investment styles.

The second part of the data analysis establishes the relationship between investment style consistency score and one-year-ahead risk-adjusted performance. The research works with one-year-ahead performance data in order to establish a cause-and-effect relationship. By including lagged return values, we can proof that style consistency influences risk-adjusted returns in some kind of way and not that current performance caused a certain form of style consistency.

Risk-adjusted performance is approximated by mutual funds' alpha scores when regressing fund returns in excess of the risk-free rate (approximated by the one-month Treasury Bill Rate) to either the CAPM model, the Fama French model or the Carhart Four-Factor model. The three regressions for every mutual fund in order to get alpha scores are given below: 


$$
\begin{array}{cl}
\text { I. } & R_{j t}-R_{f}=\alpha+\beta_{1}\left(R_{m}-R_{f}\right)+\varepsilon_{t} \quad \text { (CAPM model); } \\
\text { II. } & R_{j t}-R_{f}=\alpha+\beta_{1}\left(R_{m}-R_{f}\right)+\beta_{2}(S M B)+\beta_{3}(H M L)+\varepsilon_{t} \quad \text { (Fama-French model); } \\
\text { III. } & R_{j t}-R_{f}=\alpha+\beta_{1}\left(R_{m}-R_{f}\right)+\beta_{2}(S M B)+\beta_{3}(H M L)+\beta_{4}(M O M)+\varepsilon_{t} \text { (Carhart Four-Factor model); }
\end{array}
$$

where $R_{j t}=$ Return of mutual fund $j$ at time $t ; R_{f}=$ Risk-free rate at time $t ; b_{j k}=$ Beta of the other objective indices; $S M B=$ self-financing portfolio long in small-cap stocks and short in large-cap stocks; $H M L=$ self-financing portfolio long in stocks with a high ratio of book-to-market equity and short in stocks with a low ratio of book-tomarket equity; MOM = self-financing portfolio with long in stocks with positive momentum and short in stocks with a negative momentum over the last 6 months.

The first model explains mutual funds' excess returns by the market excess returns, known as the CAPM. The Fama French model builds upon the CAPM, and adds two self-financing portfolios, which are the small-minus big portfolio (going long in small-cap stocks and short in large-cap stocks) and the high-minus-low portfolio (going long in stocks with a high book-to-market equity ratio and short a low book-to-market equity ratio). Thus, it accounts for cross-sectional variations in return, i.e. the small-cap and value stocks premiums, which are not explained by CAPM. The third model, namely the Carhart Four-Factor Model, is a further extension of the Fama French model and adds another self-financing portfolio, which is long in stocks with a positive momentum and short in stocks with a negative momentum over the last six months, to capture the momentum effect often observed in financial markets. All three models attempt to explain risk-adjusted performance by including certain risk factors in their regressions. Further explanations of the three models are outside of the scope of the research at hand.

Alpha scores in all of the three models correspond to the intercept in a regression of portfolio excess returns against the relevant predictors. In theory, alpha is expected to equal zero since no portfolio should be able to consistently generate excess returns over what could be explained by the mentioned multifactor models (Berk \& DeMarzo, 2007). In practice, alpha scores are different to zero and they provide a measure of risk-adjusted fund performance. While positive alpha scores represent excess risk-adjusted performance, negative alpha scores represent deficient risk-adjusted performance. For each mutual fund, three alpha scores are derived and used to explore if they differ for the first, third and fifth quintile of consistency scores for the total list of mutual funds and within each of the nine stated investment style groups. This is done by performing two-sample t-test (twosided) of each of the three alpha scores between the three groups.

\section{Results}

Congruent to the data analysis, the results section is separated into two parts. While the preceding part provides an overview of the proportion of style-consistent mutual funds and the directions of deviations, the succeeding one describes obtained results for the relationship between investment style consistency and risk-adjusted performance.

\subsection{Investment Style Consistency}

When examining all U.S. equity-focused mutual funds, it stands out that a considerable large proportion can actually be classified to be inconsistent with their stated investment style. In the whole period from 2003-2015, for $49.4 \%$ all mutual funds $(n=2867)$ the respective style-specific index did not exhibit the highest beta in the return-based style analysis and thus are inconsistent with their designated style benchmark. Those funds did not adequately follow the stated investment style as indicated by their respective Lipper Classification Code. Dividing
$10 \mid$\begin{tabular}{l|l} 
Marble \\
Research
\end{tabular}
Papers 
the sample, $46.6 \%$ of all mutual funds before the financial crisis $(n=1191)$ and $51.37 \%$ of all mutual funds after the financial crisis $(n=1676)$ engaged in style drifts from their stated investment objective. This sheds light to the omnipresence of inconsistent investment behavior of mutual funds in today's financial markets.

From 2003 to 2008, most style inconsistency can be found among all blend-oriented funds (i.e. funds with a stated focus on stocks with a medium price-to-earnings and price-to-book ratio), mid-cap value funds and smallcap value funds.

For large-cap blend funds $(n=216), 76.39 \%$ were inconsistent in following their stated investment style. Out of all these inconsistent funds, $72.12 \%$ stuck to either a large-cap value or a large-cap growth investment style strategy, showing that most funds deviated to other large-cap investment styles. In addition, $82.28 \%$ of all midcap blend funds $(n=79)$ did not consistently follow their designated investment style. Most of these inconsistent mid-cap blend funds deviated towards mid-cap growth stocks (30.77\%) or mainly put their money on current accounts (18.46\%), approximated by the four-week Treasury bill rate, and saving accounts (21,54\%), approximated by 20 -years Treasury securities. For small-cap blend funds $(n=168), 76.19 \%$ showed inconsistent investment behavior in following their stated investment style. These inconsistent small-cap blend funds mostly deviated towards small-cap value (24.22\%) and small-cap growth (49.22\%) investment strategies. Since blend funds have more latitude in the companies they can invest in and their investments only on average need to have a medium price-to-earnings ratio, it becomes plausible that blend funds show the highest proportion of inconsistency. Despite their wider latitude, it is still critical that so many blend mutual funds did not follow the designated benchmark.

With respect to value-oriented mutual funds, $62.12 \%$ of all mid-cap value funds $(n=66)$ and $51.35 \%$ of all smallcap value funds $(n=74)$ were inconsistent in following the offering memorandum 's investment style. The largest group of inconsistent mid-cap value funds (39.02\%) drifted towards mid-cap blend stocks. Among all inconsistent small-cap value funds, $26.32 \%$ deviated towards small-cap blend and $28.95 \%$ primarily invested their money in current bank accounts.

From 2008 to 2015, the highest proportion of inconsistent mutual funds once again was prevalent among all blend-oriented funds, mid-cap value funds and small-cap value funds.

Amid large-cap blend funds $(n=216)$, a total of $73.12 \%$ exhibited an inconsistent investment style behavior. Most of these inconsistent large-cap blend funds drifted towards large-value stocks (46.25\%) and towards current bank accounts $(26.88 \%)$. Mid-cap blend funds $(n=105)$ had the highest share of inconsistent funds with a proportion of $95.24 \%$ altogether. The majority of inconsistent mid-cap blend funds rather followed a mid-cap growth strategy $(57.00 \%)$ or put their money on current bank accounts $(13.00 \%)$. For small-cap blend funds $(n=258), 77.52 \%$ were inconsistent in following their stated investment style. Out of all inconsistent small-cap blend funds, $58.50 \%$ stuck to either a small-cap value or small-cap growth investment style strategy.

Apart from blend-oriented mutual funds, $65.71 \%$ of all mid-cap value funds $(n=35)$ and $50.00 \%$ of all small-cap value funds $(n=92)$ did not consistently followed their stated investment style. Most of the inconsistent mid-cap value funds shifted towards large-cap value funds (43.48\%) or primarily invested their money in current bank accounts (30.43\%). Among all inconsistent small-cap value funds, a total of $69.56 \%$ put their money rather in current bank accounts or saving accounts.

To sum up, the majority of inconsistent blend-oriented mutual funds either drifted towards value and growth stocks with the same capitalization or invested their money primarily in current bank and saving accounts. Inconsistent value funds before the financial crisis tended to deviate either towards blend stocks with the same capitalization, or towards current bank and savings accounts. After the financial crisis, inconsistent value funds mainly drifted towards value stocks with a different capitalization and towards current bank and saving accounts. 
In contrast, growth-oriented mutual funds have been relatively consistent in following their stated investment style.

\subsection{Investment Style Consistency and Risk-adjusted performance}

In order to investigate whether risk-adjusted performance, measured by the three alpha scores, differs for mutual fund with varying degrees of investment style consistency, the first, third and fifth quintile of consistency scores are compared. It is worth mentioning that there are quintiles for all mutual funds together and within the nine specific investment style categories. Funds included in one of the three quintiles for the overall group must not necessarily also be in the same quintile within their respective style category, but usually they are.

While the first quintile represents style-inconsistent mutual funds with the lowest consistency scores, the fifth quintile aggregates all mutual funds with the highest consistency score, which consistently follow their stated investment style. The third quintiles functions as the midpoint of those two extremes and represents mutual funds who partly stick to their stated investment style, but occasionally also allow style drifts.

\subsubsection{3-2008}

Aggregating the risk-adjusted performance scores for all relevant mutual funds in the period from January 2003 to July 2008, it stands out that the three alpha scores, measuring risk-adjusted performance, are on average the highest for the third quintile. Hence, mutual funds that manage to balance investing in stocks from the stated investment styles and other investment styles, were able to exhibit the greatest risk-adjusted performance on average. The fifth quintiles had the second-highest alpha scores and the first quintile the lowest alpha scores on average for all three models.

With respect to CAPM alpha scores, the average for the first quintile is significantly lower than the average for both the third quintile $(p<0.01)$ and fifth quintile $(p<0.01)$. Moreover, while the average for the third quintile is higher than for the fifth quintiles, this difference is not statistically significant $(p \approx 0.55)$.

Considering three-factor model alpha scores, the average for the third quintile is significantly higher than the average for both the first quintile $(p<0.01)$ and the fifth quintile $(p<0.05)$ at a five percent confidence interval. The average for the fifth quintile is slightly higher than for the first quintiles, yet this difference is not statistically significant $(p \approx 0.24)$.

Similar to the three-factor model alpha scores, the Carhart four-factor model reveals that alpha scores for the third quintile are significantly higher than for the first and fifth quintile. While alpha scores for the fifth quintile in this particular model are slightly below alpha scores for the first quintile, this difference is again not statistically significant.

Abovementioned results suggest an inversed $U$-shaped curve for the relationship between investment style consistency and risk-adjusted performance, in which average alpha scores for the third quintile turn out to be the highest. Furthermore, the average alpha scores for fifth quintile, i.e. fund with high style consistency, are slighter higher than for the first quintile, i.e. fund with high style inconsistency. All average alpha scores and relevant test statistics can be extracted from table 1 .

\footnotetext{
$12 \mid$\begin{tabular}{l|l} 
Marble \\
Research
\end{tabular} Papers
} 
Table 1: Risk-adjusted performance scores: 2003-2008

\begin{tabular}{|c|c|c|c|c|c|}
\hline $\begin{array}{l}\text { Overall rank based on } \\
\text { average alpha }\end{array}$ & Quintile & $\begin{array}{l}\text { Average CAPM } \\
\text { alpha }\end{array}$ & $\begin{array}{l}\text { Average Three- } \\
\text { Factor alpha }\end{array}$ & $\begin{array}{l}\text { Average } \\
\text { Carhart alpha }\end{array}$ & $\begin{array}{l}\text { Average } \\
\text { total }\end{array}$ \\
\hline 3. & First quintile & -0.000560 & -0.000727 & -0.001691 & -0.000993 \\
\hline 1. & Third quintile & 0.001519 & 0.000978 & -0.000190 & 0.000769 \\
\hline 2. & Fifth quintile & 0.001131 & -0.000085 & -0.001920 & -0.000291 \\
\hline \multicolumn{6}{|c|}{ P-values for statistical tests } \\
\hline \multicolumn{2}{|c|}{ T-test for first-fifth quintile } & 0.007372 & 0.236037 & 0.681777 & \\
\hline \multicolumn{2}{|c|}{ T-test for first-third quintile } & 0.001082 & 0.001494 & 0.004791 & \\
\hline \multicolumn{2}{|c|}{ T-test for third-fifth quintile } & 0.553606 & 0.042166 & 0.000706 & \\
\hline
\end{tabular}

At this point, it remains interesting to examine which of the nine investment styles mainly influenced such an convex curve.

With respect to large-blend funds, for instance, which represent the largest group, its third quintile also had the highest alpha scores on average compared to the first and third quintile. In a similar fashion, the third quintile of small-value funds had the highest average performance as measured by the alpha scores. For the other investment styles, it stands out that their respective third quintile managed to be the worst-performing group only twice, while both the first and the fifth quintile, i.e. the very style-consistent and style-inconsistent, turned out to perform the worst several times. Hence, mutual funds, which mostly follow their stated investment style and partly allow their investment strategy to drift, only rarely performed worse than their very consistent and very inconsistent peers and for the greatest group of mutual funds, large-blend funds, they proved to be the best performing segment.

Furthermore, several characteristics of mutual funds belonging to the overall first, third and fifth quintile were examined, including expense ratio, turnover ratio, total net asset value, average portfolio age and management fees. Results can be seen in table 2 .

Table 2: Grouping of mutual funds between 2003-2008 and group-specific characteristics

\begin{tabular}{lllllll}
\hline 2003-2008 & $\begin{array}{l}\text { Average } \\
\text { consistency } \\
\text { score }\end{array}$ & $\begin{array}{l}\text { Expense } \\
\text { ratio }\end{array}$ & $\begin{array}{l}\text { Turnover } \\
\text { ratio }\end{array}$ & $\begin{array}{l}\text { Total net } \\
\text { asset value }\end{array}$ & $\begin{array}{l}\text { Average } \\
\text { portfolio age }\end{array}$ & $\begin{array}{l}\text { Management } \\
\text { fees }\end{array}$ \\
\hline 1. Quintile & -1.0000 & 0.0159 & 0.9388 & 448.7976 & 17.81 & 0.6859 \\
3. Quintile & 0.3385 & 0.0147 & 0.8957 & 363.5574 & 18.96 & 0.6685 \\
5. Quintile & 0.8415 & 0.0143 & 0.8801 & 418.3242 & 19.96 & 0.6684 \\
\hline
\end{tabular}

The average investment style consistency scores for the first quintile (very inconsistent mutual funds) was -1, for the third quintile was 0.3385 and for the fifth quintile (very consistent mutual funds) 0.8415 . In line with Brown et. al. (2009), it stands out that more style-inconsistent mutual funds exhibit a higher turnover ratio, which is the minimum of aggregated sales or purchases of securities divided by the average 12-month total net assets of a fund (CRSP, 2016). Yet, the discovered difference is not statistically significant. With regards to average portfolio age, the fifth quintile turns out to be slightly older than both the first and third quintile by two and one year respectively. The first quintile further has the largest average net asset value, followed by the fifth quintile and the third quintile. Lastly, very style-inconsistent mutual funds tend to have higher expense ratios and management fees than very style-consistent funds. The third quintile appears to be in the middle, although 
both ratios are considerably closer to the value for the fifth quintile. A more comprehensive interpretation of abovementioned results is given in the discussion section.

\subsubsection{8-2015}

Similar to the preceding section, the first step aggregates risk-adjusted performances scores for all relevant mutual funds in the database from August 2008 to December 2015. Remarkably, it becomes apparent that the explored inversed U-shape form for risk-adjusted performance before the financial crisis reversed for the period under study. Total average alpha scores are lowest for the third quintile, while the fifth quintile on average performs best and the first quintile second best. Hence, mutual funds, which partly stick to their stated investment style and occasionally allow their style to drift, appear to be stuck in the middle with inferior performance. In contrast, being either largely consistent or largely inconsistent with one's stated investment style, appears to be associated with better risk-adjusted returns.

Regarding CAPM alpha scores, the average for the fifth quintile is significantly larger than the averages for the first quintile $(p<0.01)$ and the third quintile $(p<0.01)$. The third quintile has a marginally higher average, but this difference is far from being significant $(p \approx 0.86)$.

Coming to alpha scores for the three-factor model, it stands out that the third quintile exhibits significantly lower values than both the first quintile $(p<0.01)$ and fifth quintile $(p<0.01)$. While alpha scores for the fifth quintile are slightly higher than for the first quintile, the two-sample t-test reveals an insignificant $\mathrm{p}$-value $(p \approx 0.20)$.

The Carhart four-factor model once more reveals results analogous to the three-factor model, which is a demonstration for their affinity. Under the Carhart model, alpha scores for the third quintile are significantly lower than for both the first quintile $(p<0.01)$ and fifth quintile $(p<0.01)$, whereas a slightly higher alpha average of the fifth quintile compared to the first quintile turns out to be insignificant once more $(p \approx 0.64)$.

Hence, the results at hand suggest a U-shaped relationship between investment style consistency and riskadjusted performance. In that relationship, the third quintile, i.e. funds partly following the stated investment style, perform significantly worse than funds which either closely follow the investment objective or consequently allow their investment style to drift to other investment styles. Similar to the period before the financial crisis, the fifth quintile performs slightly better than the first quintile, although this difference is only significant for the CAPM model. All average alpha scores and relevant test statistics can be extracted from table 3 .

Table 3: Risk-adjusted performance scores2008-2015

\begin{tabular}{|c|c|c|c|c|c|}
\hline $\begin{array}{l}\text { Overall rank based on } \\
\text { average alpha }\end{array}$ & Quintile & $\begin{array}{l}\text { Average CAPM } \\
\text { alpha }\end{array}$ & $\begin{array}{l}\text { Average Three- } \\
\text { Factor alpha }\end{array}$ & $\begin{array}{l}\text { Average } \\
\text { Carhart alpha }\end{array}$ & $\begin{array}{l}\text { Average } \\
\text { total }\end{array}$ \\
\hline 2. & First quintile & -0.001851 & -0.001276 & -0.001029 & -0.001385 \\
\hline 3. & Third quintile & -0.001791 & -0.002185 & -0.002072 & -0.002016 \\
\hline 1. & Fifth quintile & 0.000537 & -0.000923 & -0.000887 & -0.000424 \\
\hline \multicolumn{6}{|c|}{ P-values for statistical tests } \\
\hline \multicolumn{2}{|c|}{ T-test for first-fifth quintile } & 0.000000 & 0.203584 & 0.635888 & \\
\hline \multicolumn{2}{|c|}{ T-test for first-third quintile } & 0.863437 & 0.002966 & 0.001410 & \\
\hline \multicolumn{2}{|c|}{ T-test for third-fifth quintile } & 0.000000 & 0.000104 & 0.00254 & \\
\hline
\end{tabular}

Again, it is of interest to explore the individual investment style categories functioning as the main driver behind such a concave relationship between investment style consistency and risk-adjusted performance.

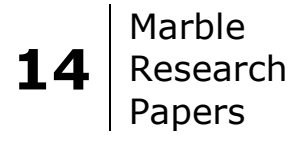


It stands out, that the third quintile of large-blend, large-value, mid growth, and small-blend mutual funds had the lowest average alpha scores compared to the first and fifth quintiles. The third quintiles, therefore, does not only show inferior risk-adjusted performance in a variety of individual investment style categories, but these categories also represents some of the largest groups and have a relatively heavy weight in the overall analysis. On top, the third quintile only manages to have superior risk-adjusted performance within one style category, namely small-growth, while the first quintile is the best performing group in three categories and the fifth quintile in five individual categories.

To sum up, while the first quintile, i.e. very inconsistent mutual funds, and the fifth quintile, i.e. very consistent mutual funds, have roughly similar risk-adjusted performance with a slight superiority for the fifth one, the third quintiles turns out to exhibit significantly worse risk-adjusted returns.

As for mutual funds before the financial crisis, a characteristics-based analysis of the individual quintiles was undertaken. The summary of results can be seen in table 4.

Table 4: Grouping of mutual funds between 2008-2015 and group-specific characteristics

\begin{tabular}{lllllll}
\hline 2008-2015 & $\begin{array}{l}\text { Average } \\
\text { consistency } \\
\text { score }\end{array}$ & $\begin{array}{l}\text { Expense } \\
\text { ratio }\end{array}$ & $\begin{array}{l}\text { Turnover } \\
\text { ratio }\end{array}$ & $\begin{array}{l}\text { Total net } \\
\text { asset value }\end{array}$ & $\begin{array}{l}\text { Average } \\
\text { portfolio age }\end{array}$ & $\begin{array}{l}\text { Management } \\
\text { fees }\end{array}$ \\
\hline 1. Quintile & -1.0000 & 0.0116 & 0.8433 & 367.7931 & 15.09 & 0.5312 \\
3. Quintile & 0.0468 & 0.0115 & 0.8102 & 299.2516 & 10.84 & 0.5209 \\
5. Quintile & 0.8704 & 0.0108 & 0.7476 & 357.2281 & 15.96 & 0.4794 \\
\hline
\end{tabular}

The average investment style consistency scores for the first quintile (very inconsistent mutual funds) was -1 , for the third quintile was 0.0468 and for the fifth quintile (very consistent mutual funds) 0.8704 . Congruent to prior research, very style-consistent mutual funds have a lower turnover ratio than more style-inconsistent mutual funds, although the differences are not statistically significant. Once again, the first quintile exhibits the highest average net asset value, followed by the fifth and the first quintile. In contrast to the period before the financial crisis, there is a significant difference in the average portfolio age. While the first and fifth quintiles roughly have the same average age, the third quintile lies substantially below with an average age of 10.84 . Moreover, while very style-inconsistent mutual funds tend to have higher expense ratios and management fees as their more passive style-consistent counterparts, the third quintile this time has an expense ratio and management fees that are closer to the first quintile. Before the financial crisis, the third quintile's values were closer to the fifth quintile. A potential explanation is given in the following discussion section. Overall, average values for expense ratio, turnover ratio, net asset value and management fees are on a lower level than before the financial crisis. 


\section{Discussion}

Results from the preceding section suggest that while very style-consistent and style-inconsistent funds exhibit relatively similar returns, they are slightly higher for the ones with higher consistency before and after the financial crisis. These results suggest that active fund managers, who often engage in style drifts to benefit from the potential upside of style-rotation or momentum effects, are not able to generate higher net returns to investors. Although mutual funds may increase gross returns through superior stock-picking skills, that process entails additional management fees and transaction costs that outweigh any benefits. This can be seen by the higher turnover ratio, which causes higher transaction costs, and management fees that the first quintile exhibits. Therefore, the study at hand does not proof active, style-drifting fund managers to be not able to generate higher gross return through superior stock-picking skills. It merely proofs that these additional gross returns are not substantial enough to outweigh additional costs inherent in the stock-picking process. These findings are in line with previous studies (Daniel, Grinblatt, Titman, \& Wermers, 1997; Grossman, Sanford, \& Stiglitz, 1980) which found that active mutual funds beat mechanical strategy by only a small amount and this amount approximately equals average management fees.

Although mutual funds provide numerous services, including check-writing and bookkeeping activities, more than half of its expenses occur due to their stock-selection efforts (Daniel, Grinblatt, Titman, \& Wermers, 1997). Hence, mutual funds need to balance the costs of searching for and analyzing promising stocks with potential benefits of additional gross returns. In that fashion, Carhart (1997) analyzed the relation between performance and expense ratio and found evidence that, on average, funds do not recover investment costs through higher returns. Yet, the top-performing mutual funds were still able to increase net returns, which provides evidence for the possibility of active fund management to deliver superior returns to investors.

Before the financial crisis, the third quintile proved to be the best-performing group overall. Since their average turnover ratio (0.896) and consistency score (0.339) were relatively close to the means of very style-consistent mutual funds ( 0.880 and 0.842 respectively), the third quintile did not engage in a multitude of style-drifts. These funds managed to pick certain "hot" stocks for the few deviations they had and were able to do that with relatively little efforts. In fact, the third quintile only showed a minor increase in its expense ratio and management fees as compared to the fifth quintile. This testifies that these mutual funds managed to get some exposure to the upside potential of style drifts in an efficient way by keeping investment costs low. Hence, mutual funds, which mostly followed their stated investment style and partly engaged in deliberate stylerotations, were able to benefit from the upside potential of style-drifts.

To sum up, it appeared to be possible to engage in a few style deviations with relatively little efforts as some investment opportunities were easily detectable. Very style-inconsistent mutual funds, in contrast, invested in a variety of stocks from other investment styles and not only in a few "hot" stocks. They faced a high expense ratio as it likely became increasingly cumbersome to detect good investments beyond those "hot" stocks and they probably engaged in certain asset misallocations. Therefore, these mutual funds did not manage to increase net return to investors as compared to passive, style-consistent funds.

In the period after the financial crisis, the relationship between style consistency and risk-adjusted performance reversed and the third quintile turned out to be the worst performing group. This illustrates that the financial crisis with its all-encompassing consequences for the world economy and financial markets had a significant impact on the work of fund managers.

In relative terms to the first and fifth quintile, the third quintile was more active than in the period before the financial crisis, as visible in its lower consistency score (0.047) and a turnover ratio (0.810) that is closer to the average of the first quintile (0.843), i.e. very style-inconsistent mutual funds. Similarly, the aggregated expense

$16 \mid$\begin{tabular}{l|l} 
Marble \\
Research
\end{tabular} Papers 
ratio and management fees rather approached the averages for the first quintile. Hence, mutual funds, which mostly followed their stated investment style and partly engaged in style drifts, had relatively high investment costs for the transacted investments, and ended up with inferior net returns to investors. This indicates that after the financial crisis it became intricate to detect a few "hot" stocks providing relatively safe investment returns with only little efforts. Fund managers have to commit more resources in their stock-selection process to be able to increase return to investors. The third quintile, therefore, seems to be stuck in the middle. Furthermore, mutual funds belonging to the third quintile were significantly younger on average than the other two quintiles, such that those funds are likely to have been less experienced. In contrast, very style-inconsistent mutual funds went the extra mile and undertook more efforts in their stock-selection process as visible in a higher expense ratio and turnover ratio, which payed off eventually in the form of higher net returns to investors.

Hence, after the financial crisis the relationship between investment style consistency and risk-adjusted performance reversed in an interesting way. The results suggest that it was not possible any longer to pick a few promising investment opportunities with little efforts. In case mutual funds decided to engage in style drifts, they have to go the full way in their stock-selection process and invest in a variety of promising stocks from other investment styles.

\section{Limitations \& Concluding Remarks}

The research at hand investigates the relationship between investment style consistency of mutual funds and subsequent risk-adjusted performance before and after the financial crisis. It employs a novel consistency ratio to measure style consistency based on the return-based style-analysis, which is commonly used in many studies. The results discover that a significant proportion, totaling 49.4\% all mutual from 2003 to 2015, did not closely follow their stated investment style. Individual investors entrust their money to fund managers based on the investment strategy promised in the offering memorandum and a coherent investment style enables those investors to manage the risk and return profile of their aggregate portfolio. Considering this fact, the large number of style-inconsistent mutual funds might be interpreted as an alarming signal, complicating effective overall portfolio management for diversified investors.

Yet, the study reveals that in the period of 2003 to 2008 mutual funds, which partly followed their stated investment style and occasionally deviate towards other investment styles, on average exhibited superior riskadjusted returns as compared to strongly consistent and inconsistent funds. One can refer to a convex relationship between style consistency and risk-adjusted performance. This gives evidence to the potential benefits of occasional and deliberate style-rotation for fund managers in the time before the financial crisis. For the post financial crisis period of 2008 to 2015, the relationship reverses, giving rise to a concave relationship between style consistency and risk-adjusted performance. In recent years, it has been more beneficial to strictly style-rotate or to completely stick to the stated investment style due to a likely difficulty of detecting a few promising stocks with little efforts. The research furthers investigates certain characteristics of mutual funds with an inconsistent investment behavior to its stated investment style. It finds that those funds are associated with a higher averaged turnover ratio, expense ratio and management fees. Hence, these characteristics can be employed by investors to detect style-inconsistent mutual funds.

As common in almost every research endeavor, the study faces certain limitations. In fact, the dataset under study is limited to mutual funds with a non-changing stated investment style objective during the whole period to get meaningful regression parameters with the return-base style analysis. Otherwise, the data analysis would have been significantly complicated. This approach, however, has excluded a certain amount of funds, which might have an impact on the validity of the findings. 
Furthermore, only U.S. equity mutual funds have been investigated over a relatively short period of twelve years. There is decent likelihood that the findings are generally applicable and that they can be extrapolated to other financial markets around the world, as well. Yet, this needs to be validated by further studies.

Lastly, the study at hand elaborates a distinct method to obtain scores for investment style consistency that slightly differs from the work of other researches. For instance, Brown et. al. (2009) work with a measure called RSQ, which captures the portion of a fund's return variance that cannot be explained by the co-movements to a single style benchmark. The two methods slightly vary from each other, although in theory their consistency scores should be strongly positively correlated.

The findings shown in the study at hand contribute to current research on investment style consistency, by suggesting a convex and concave curve of mutual funds' performance. Previous studies almost exclusively suggest a linear relationship between investment style consistency and risk-adjusted performance. This focus on linearity is a potential reason for widespread controversial results. Future studies, therefore, should more fully explore the potential of nonlinear relationships between investment style consistency and risk-adjusted performance to explain fund managers' investment behavior.

\section{References}

Asness, C. S., Friedman, J. A., Krail, R. J., \& Li. (2000). Style timing: Value versus growth. The Journal of Portfolio Management, 26(3), 50-60.

Banz, R. W. (1981). The Relationship Between Return and Market Value of Common Stocks. Journal of Financial Economics, 9, 3-18.

Barberis, N., \& Shleifer, A. (2003). Style investing. Journal of Financial Economics, 68(2), 161-199.

Baron, R. M., \& Kenny, D. A. (1986). The moderator-mediator variable distinction in social psychological research: Conceptual, strategic, and statistical considerations. Journal of Personality and Social Psychology, 51, 1173-1182.

Barry, C. B., \& Brown, S. J. (1984). Differential information and the small firm effect. Journal of Financial Economics, 13(2), 283-294.

Berk, J., \& DeMarzo, P. (2007). Corporate Finance. Pearson Education.

Bollen, N. P., \& Busse, J. A. (2001). On the timing ability of mutual fund managers. The Journal of Finance, 56(3), 1075-1094.

Brown, K. C., Van Harlow, W., \& Zhang, H. (2009). Staying the course: The role of investment style consistency in the performance of mutual funds.

Carhart, M. M. (1997). On persistence in mutual fund performance. The Journal of finance, 52(1), 57-82.

CRSP. (2016). Fund Fees "FUND_FEES". Retrieved June 15, 2016, from CRSP - Center for Research and Security Prices: http://www.crsp.com/products/documentation/fund-fees-\%E2\%80\%9Cfundfees\%E2\%80\%9D

CRSP. (2016). Lipper Objective and Classification Codes. Retrieved May 09, 2016, from CRSP - Center for Research and Security Prices: http://www.crsp.com/products/documentation/lipper-objective-andclassification-codes

Daniel, K., Grinblatt, M., Titman, S., \& Wermers, R. (1997). Measuring mutual fund performance with characteristic-based benchmarks. The Journal of finance, 57(3), 1035-1058. 
Dor, A. B., \& Jagannathan, R. (2002). Understanding mutual fund and hedge fund styles using return based style analysis. National Bureau of Economic Research.

Fama, E. F., \& French, K. R. (1992). The cross-section of expected stock returns. The Journal of Finance, 47(2), 427-465.

French, K. R., \& Fama, E. F. (1993). Common risk factors in the returns on stocks and bonds. Journal of Financial Economics, 33, 3-56.

French, K. R., \& Fama, E. F. (1995). Size and book-to-market factors in earnings and returns. Journal of Finance, 50, 131-155.

Froot, K., \& Teo, M. (2008). Style investing and institutional investors. Journal of Financial and Quantitative Analysis, 43(4), 883-906.

Grossman, S., Sanford, J., \& Stiglitz, J. E. (1980). On the impossibility of informationally efficient markets. The American economic review, 70(3), 393-408.

Huang, J., Sialm, C., \& Zhang, H. (2011). Risk shifting and mutual fund performance. Review of Financial Studies, 24(8), 2575-2616.

Jiang, G. J., Yao, T., \& Yu, T. (2007). Do mutual funds time the market? Evidence from portfolio holdings. Journal of Financial Economics, 86(3), 724-758.

Lai, K. S., \& Lai, M. (1991). A cointegration test for market efficiency. Journal of Futures Markets, 11(5), 567575.

Levis, M., \& Liodakis, M. (1999). The profitability of style rotation strategies in the United Kingdom. The Journal of Portfolio Management, 26(1), 73-86.

Reinganum, M. R., \& Smith, J. K. (1983). Investor preference for large firms: new evidence on economies of size. The Journal of Industrial Economics, 213-227.

Shukla, R., Kim, M., \& Tomas, M. (2000). Mutual fund objective misclassification. Journal of Economics and Business, 52(4), 309-323.

Wermers, R. (2012). Matter of style: The causes and consequences of style drift in institutional portfolios.

White, H. (2000). A reality check for data snooping. Econometrica, 68(5), 1097-1126.

Zhao, Y. (2009). "Does mutual fund investment style consistency affect the performance of mutual funds?: evidence from Chinese mutual funds.". 